\title{
A GESTÃO BIOPOLÍTICA DO TERRITÓRIO NAS GRANDES CIDADES: INCLUSÃO/EXCLUSÃO E ABANDONO
}

\section{THE BIOPOLITICAL MANAGEMENT OF THE TERRITORY IN THE BIG CITIES: INCLUSION/EXCLUSION AND ABANDONMENT}

\section{Marcus Vinícius Xavier de Oliveira ${ }^{1}$}

\begin{abstract}
Resumo
Este ensaio tem por escopo tentar comprovar que o alegado défice do princípio da territorialidade, geralmente utilizado como um cânon argumentativo pela teoria da globalização, não passa de um trompe-l'oiel ,e que a operatividade e eficácia desse princípio, por ter sido capitado pelo mercado e pelo sistema econômico global, continua a operar amplas formas de exclusão e abandono contra as camadas mais frágeis da população, em especial nas metrópoles. Para tanto, no primeiro tópico buscou-se comprovar a vigência de referido princípio nas atuais sociedades nacionais, bem como o fato de que, tendo este princípio sido captado pelo sistema hegemônico do capitalismo transnacional, faz do sistema penal o principal elemento de controle da exclusão da população. No segundo tópico é apresentado e discutido - referencial teórico que deu suporte ao ensaio, a saber, a biopolítica, cuja principal compreensão está contida na famosa díade foucaultiana "fazer viver ou deixar morrer". No terceiro tópico faz-se uma interpretação desses processos de inclusão minoritária e exclusão/abandono de maioria da população a partir de seus efeitos concretos, em especial, o estranhamento nas grandes cidades, os espaços privatizados de segurança e bem-estar, e de outro lado, nos espaços de exclusão e abandono em que, não os direitos e garantias fundamentais, mas o sistema penal através de suas agências que atuam violentamente. 0 método de procedimento adotado foi o de pesquisa bibliográfica, tendo como método científico o crítico.
\end{abstract}

Palavras chave: Gestão Biopolítica. Metrópole. Sistema Penal-Violência Institucional. Inclusão/Exclusão. Abandono

\begin{abstract}
This essay attempts to prove that the alleged shortcoming of the principle of territoriality, generally used as an argumentative canon by the theory of globalization, is nothing more than a trompe l'oeil, and that the operability and efficacy of this principle, by the market and by the global economic system, continues to operate ample forms of exclusion and abandonment against the more fragile sections of the population, especially in the metropolises. For this purpose, the first topic sought to prove the validity of said principle in the current national societies, as well as the fact that, having this principle been captured by the hegemonic system of transnational capitalism, makes the criminal system the main element of control of exclusion of the population. The second topic is presented and discussed on the theoretical framework that supported the essay, the biopolitics, whose main understanding is contained in the famous Foucauldian dyad "right to live or let to die". The third topic is an interpretation of these processes of minority inclusion and exclusion / abandonment of the majority of the population based on their concrete effects, in particular, estrangement in large cities, privatized spaces for

\footnotetext{
${ }^{1}$ Professor Adjunto da Universidade Federal de Rondônia. Doutor em Direito Penal pela Universidade do Estado do Rio de Janeiro. Membro do Grupo de Pesquisa em Teoria Política Contemporânea. E-mail: marcusoliveira@unir.br
} 
security and well-being, and on the other hand, in the areas of exclusion and abandonment in which, not the fundamental rights and guarantees, but the criminal system through its agencies acting violently. The method of procedure adopted was that of bibliographical research, having as critical scientific method.

Keywords: Biopolitical Management. Metropolis. Criminal System-Institutional Violence. Inclusion/Exclusion. Abandonment 


\section{CONSIDERAÇÕES INICIAIS}

Os conceitos políticos fundamentais que gizam a cultura ocidental parecem gozar de um estranho atributo quando analisados sob a perspectiva da história das ideias, a saber: a possibilidade de, em determinados momentos, serem solapados para fora do locus discursivo, como se houvessem perdido, por um gesto da fortuna, este seu status, e merecessem, quando muito, uma remissão no âmbito de algum léxico político-filosófico que registrasse o seu défice.

Ora, é sabido que em política não existe acaso, sorte ou fortuna, esta deusa cujo humor demasiadamente fugaz detinha o poder, segundo o pensamento político medieval, em elevar e derrubar reis e soberanos conforme the aprouvesse, como, e.g., deixou registrado o gravurista alsaciano Herrade de Landsberg nessa iluminura que compõe o Hortus Deliciarum, cuja cópia está depositada na Biblioteca Nacional da França (Apud COSTA, ZIERER, 2011):

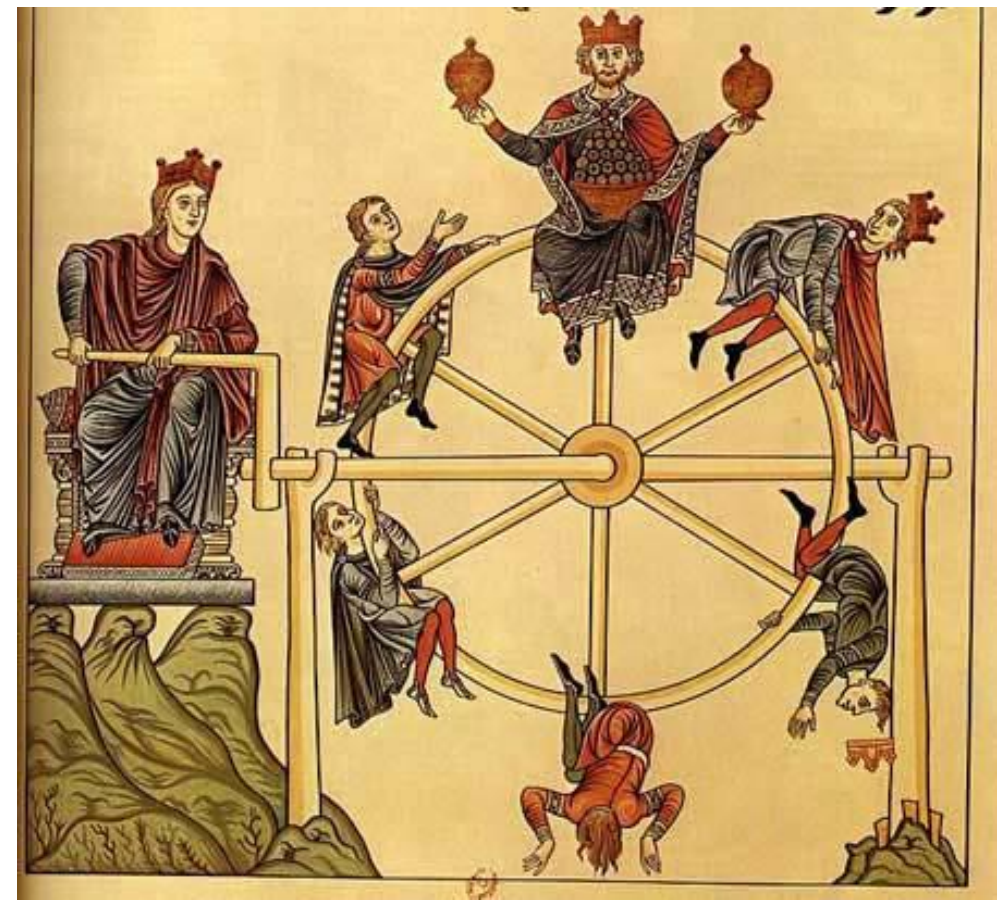

Não, em política, o uso ou o défice de um conceito político fundamental está condicionado à capacidade que os grupos políticos hegemônicos detêm na forma de uma supradeterminação da dialogicidade no espaço público, e que tem por característica principal a determinação da substituição de um conceito por outro, como se, pelo simples fato da ocultação, ele deixasse de operar eficácia semântica e sintática na compreensão da realidade na forma de um trompe-l'oeil, como, ademais, é expressamente reconhecido e defendido inter alia por Giorgio Agamben ao discorrer sobre o caráter político-teológico da política moderna (AGAMBEN, 2007, pp. 13-27). 
Pois bem. A hipótese que guia o presente ensaio consiste em reconhecer que, apesar de todo esforço despendido pelo pensamento afirmativo da globalização no pós annus mirabilis de1989 (SANTOS, 2011), com a sua afirmação de um mundo sem fronteiras e a correspectiva inclusão de todos os povos em uma nova ordem internacional com igual difusão de todas as condições de vida boa, o que levaria, doutro giro, na negação do princípio da territorialidade e a necessidade de substituir os Estados nacionais por uma comunidade transnacional, doxa que foi e continua sendo repetida ad nauseam pelo discurso neoliberal ainda hoje, por uma clara influência dessa mesma globalização, a territorialidade, enquanto conceito fundamental do pensamento político moderno continua a orientar, de forma pragmática, este enorme e eficaz processo de inclusão e exclusão que sempre caracterizou as sociedades modernas, e isso tanto no plano interno quanto no internacional, na medida em que, para atender às demandas do mercado e da economia, o território passa a ser um princípio orientador da própria ação/omissão do Estado, reconhecendo, em relação a alguns espaços, a necessidade de "investimento", que tanto conota o emprego de recursos econômicos com fins exclusivamente exploratórios, como o "desbancar" de políticas de exclusão de camadas subalternas na forma de sua expulsão do território (agora) valioso, e em relação a outros, de abandono.

Esta referência é importante porque, conforme o demonstra a realidade do sistema penal brasileiro, onde os sistemas de seguridade e assistência sociais falham, é o Direito Penal, em toda a sua ferocidade e violência que ingressa como forma de controle da pobreza e de manutenção dos processos de exclusão decididos desde parâmetros político-econômicos.

Mas é importante frisar que esses sistemas de seguridade e assistência sociais não "falham" por um acaso, por um gesto da fortuna, mas em razão de decisões orientadas pela polaridade investimento-abandono.

Conforme a feliz imagem de Davi Tangerino, ao referir-se à expansão do Direito Penal in terrae brasilis, "O Direito Penal se apresenta como Davi, mas se comporta como Golias; não apenas por sua compleição, mas também por querer ser um modesto, porém corajoso pastor e ser, em verdade, uma besta enfurecida, abusando-se da notória história bíblica" (TANGERINO, 2011, p. 155).

Interessante: se ficarmos no discurso teratológico, Thomas Hobbes (HOBBES, 1997, pp. 223-250) assimila o Estado à figura do Leviatã - o monstro bíblico narrado em Jó, Capítulo 41 -, e o Direito Penal a seus músculos, sem os quais, como no corpo animal e humano, não poderá sustentar-se nem exercer a sua força e poder. 
E não continua sendo o sistema penal este complexo muscular superexpandido com o qual o Estado, em especial o brasileiro, busca manter a todo custo uma legitimidade política há muito perdida mediante controles territoriais de inclusão e exclusão que se guiam não pela política - entendida como expressão humana por excelência - mas pela economia?

\section{O TERRITÓRIO COMO ESPAÇO SIMBÓLICO}

O princípio da territorialidade tem uma história, sendo ela, modernamente, originada naquilo que os historiadores do Direito Internacional denominam de sistema westfaliano do Direito Internacional (JOSÉ BREMER, 2013, pp. 66-67), conceito que se reporta aos diversos processos que deram fim à Guerra dos Trinta Anos na Europa setecentista (1618-1648), ao fim dos quais surgiram, como instituições internacionais independentes, os modernos estados territoriais, regidos pelos princípios da igualdade soberana e o da não intervenção em assuntos de jurisdição interna, cuja primeira manifestação não poderia deixar de ser, dado o caráter religioso daquela guerra, o princípio "cuius regius eius religio" (CASTRO, 2012, p. 36).

Este caráter "religioso" dos estados territoriais fica mais evidente ainda quando se percebe que, no léxico político, surge um "novo" conceito fundamental para o nascente estado moderno e as suas constantes transformações até o atual modelo demoliberal: tolerância. Mas tolerar a quem? Aos grupos cristãos distintos daquele que o príncipe confessava (HABERMAS, 2003, pp. 2-12).

Estados territoriais, e não nacionais, porque a grande questão que se tinha à época não era a determinação territorial em favor de uma nação, mas sim em favor de um soberano, que até então se via submetido em sua autoridade quer à Igreja Católica Apostólica Romana quer ao Imperador do Sacro Império Romano-Germânico, período este conformado historicamente pelo nome de Republica Christiana e que vigeu pelo longo período compreendido pela idade média (MIRANDA, 2005, pp. 23-26).

A rigor, somente se pode falar em Estado Nacional quando, paradigmaticamente, em 1789 a Assembleia revolucionária aprova a Declaração dos Direitos do Homem e do Cidadão, gesto com o qual, segundo Giorgio Agamben (AGAMBEN, 2013, pp. 33;50), tem-se o nascimento do regime biopolítico moderno:

No sistema do Estado-nação, os chamados direitos sagrados e inalienáveis do homem aparecem desprovidos de toda tutela e realidade precisamente no momento em que não é possível configurá-los como direitos dos cidadãos de um Estado. Se bem visto, isso está implícito na ambiguidade que entranha o próprio título da declaração de 1789: 
Déclaration des Droits de L'Homme et du Citoyen, onde não resta claro se os dois termos nomeiam duas realidades autônomas ou formam, pelo contrário, um sistema unitário no qual o primeiro já está contido e oculto no segundo e, neste último caso, que classe de relação existe entre os mesmos [...] As Declarações de Direitos representam a figura original da inscrição da vida natural no ordenamento jurídico-político do Estadonação. Aquela vida nua natural, à qual, no antigo regime, se era politicamente indiferente e pertencia, enquanto que criatura, a Deus e, no mundo clássico, era (ao menos aparentemente) claramente distinta como zoé da vida política (bíos), entra agora em primeiro plano na estrutura do Estado e até se converte no fundamento de sua legitimidade e soberania [...] Um simples exame do texto da declaração de [17]89 mostra, com efeito, que é precisamente a vida nua natural, isto é, o mero fato do nascimento, o que aqui se apresenta como fonte e portador do direito. "Les hommes", prescreve o artigo $1^{\circ}$, "naissent et demeurent libre et égaux em droits" [...]. Mas, de outra parte, a vida natural que, ao inaugurar a biopolítica da modernidade, vem assim a formar a base do ordenamento, se dissipa imediatamente na figura do cidadão, no qual os direitos "se conservam" (art. 20: "Le but de toute association politique est la conservation des droits naturels et imprescriptibles de l'homme"). E precisamente porque há posto o natural no coração mesmo da comunidade jurídica, chegado a este ponto, a declaração pôde atribuir a soberania à "nação" (art. 30: "Le príncipe de toute souveraineté réside essentiellement dans la nation"). Assim, como a nação, que etimologicamente deriva de nascere, fecha-se o círculo aberto pelo nascimento do homem.

Aqui, portanto, se encontra o 'ovo de serpente'! O território, antes visto como espaço geográfico de domínio do soberano passa a ser, por um gesto do direito, no espaço simbólico de inscrição e ingresso da vida humana na nação e no direito: não se trata mais de domínio, mas de pertencimento. A vida humana "pertence" simbolicamente à nação, que, assim como o território, passa a ser gerida em suas mínimas expressões, como as demais riquezas que demarcam a pujança ou a pobreza de um estado (FOUCAULT, 2007, pp. 281-282).

É na obra de Michel Foucault que esta transformação se torna mais evidente quando ele discorre sobre a conversão do Estado territorial, orientado pelo paradigma diplomático militar de inspiração maquiavélica, em estado de população, orientado pelo pensamento político-econômico da "polizeiwissenschaft" (o Estado de Polícia) alemã, no qual, homens e coisas são geridos de conformidade com parâmetro econômicos, e não políticos, segundo um cálculo contábil-econômico em que fato e vida se misturam nos créditos e débitos da gestão estatal (FOUCAULT, 2006, pp. 107-137; FOUCAULT, 2007, pp. 278 e ss.; AGAMBEN, 2007, pp. 911).

Esta racionalidade surgida entre os séculos XVII e XVIII utiliza o termo polícia não enquanto uma instituição que seja responsável pela segurança e paz públicas, tal qual o uso 
contemporâneo da expressão, mas sim "[...] uma técnica de governo própria ao Estado; domínios, técnicas, objetivos que apelam à intervenção do Estado". Doutro giro, o termo polícia pode designar o próprio estado nas obras dos autores que sustentam a teoria da polícia, que a usam como sinônimo de cidade, república ou estado (FOUCAULT, 2007, p. 377).

Conforme Michel Foucault, a teoria da polícia surge utópica na obra de Turquet de Mayne em 1611 e se transforma em prática governamental na ciência da administração alemã dos séculos XVIII e XIX, a "polizeiwissenschaft" (FOUCAULT, 2003, pp. 377 e ss.), ou mais especificamente,

A arte de governar, tal como aparece em toda esta literatura, deve responder essencialmente à seguinte questão: como introduzir a economia - isto é, a maneira de gerir corretamente os indivíduos, os bens, as riquezas no interior da família - ao nível da gestão de um Estado? [...] Governar um Estado significará portanto estabelecer a economia ao nível geral do Estado, isto é, ter em relação aos habitantes, às riquezas, aos comportamentos individuais e coletivos uma forma de vigilância, de controle tão atenta quanto a do pai de família [...] Quesnay fala de um bom governo como de um "governo econômico". E se Quesnay fala de governo econômico - que no fundo é uma noção tautológica, visto que a arte de governar é precisamente a arte de exercer o poder segundo o modelo da economia - é porque a economia [...] já começa a adquirir seu sentido moderno e porque neste momento se começa a considerar que é da própria essência do governo ter por objetivo principal o que hoje chamamos de economia (FOUCAULT, 2005, pp. 281-282).

A polícia deve se ocupar da administração dos aspectos positivos e negativos existentes no Estado, e que assim podem ser resumidos: enquanto manifestações positivas, o Estado deve administrar as pessoas em seus aspectos produtivos, tais como educação, determinação dos gostos e de suas aptidões, além da gestão dos bens do Estado, entendido como o conjunto de atividades produtoras de bens, entre os quais se inclui o próprio território, não mais entendido como um domínio contestado, mas sim como um domínio no qual existe uma fonte econômica público-privada de riquezas. Já em seu aspecto negativo, o Estado deve gerir aqueles aspectos negativos da vida, tais como os pobres, as viúvas e órfãos, os desempregados, bem como a saúde pública, estabelecendo as formas de enfrentamento das doenças, das epidemias, das inundações e incêndios (FOUCAULT, 2006, p. 378). Em outras palavras, a polícia tem o papel de desenvolver

[...] a "comunicação entre os homens, no sentido amplo do termo. Sem isso, os homens não poderiam viver; ou sua vida seria precária, miserável e perpetuamente ameaçada [...] Como forma de intervenção racional exercendo o poder político sobre os homens, o papel da polícia é de Ihes dar um pequeno suplemento de vida; e, assim fazendo, de dar ao Estado 
um pouco mais de força. Isso se faz através do controle da "comunicação", quer dizer, das atividades comuns dos indivíduos (trabalho, produção, troca, comodidades) [...] a polícia vela pelo vivo. (grifo nosso) (FOUCAULT, 2006, p. 379).

Mas se homens e coisas são geridos é porque, a rigor, as ideias-norte de sacralidade da vida humana, de direitos inalienáveis, de igualdade formal e controle do poder são sempre relativizadas em razão dos princípios econômicos que orientam a razão de estado no regime biopolítico.

Michel Foucault sintetizou esta compreensão na famosa inversão do regime da soberania em a História da sexualidade l: a vontade de saber: "do fazer morrer ou deixar viver" para "deixar viver ou fazer morrer" (FOUCAULT, 2005, pp. 129-130).

Assim, se antes o soberano detinha o poder de vida e morte na defesa de sua soberania, hoje o poder de vida e morte se exerce em nome e a favor da sociedade, sabendose, entretanto, que para Michel Foucault, morte não consiste só na eliminação física, mas também no abandono, na abstenção das ações necessárias para que a vida humana alcance as condições mínimas de sobrevivência, como também na expulsão política e no exílio (FOUCAULT, 2002, pp. 305-306).

Este caráter biopolítico fica mais evidente se ele for compreendido segundo o próprio paradigma utilizado por Michel Foucault. Se a lepra e a peste se manifestam como os dois paradigmas com os quais ele compreendeu a passagem do estado territorial para a sociedade disciplinar na forma daquilo que ele denomina de poder disciplinar ${ }^{2}$, ou, em outras palavras, no poder de incluir e/ou excluir indivíduos do contexto social, o problema da população enquanto elemento político do Estado é compendiado a partir do paradigma da vacinação contra a varíola (FOUCAULT, 2006, pp. 26-33).

Sendo o enfrentamento dos problemas de segurança, em sentido lato (qualquer evento, humano ou natural, que pusesse em risco a pujança econômica da sociedade, incluído aí as doenças) e estrito (a criminalidade), temas que tocavam o cerne do pensamento econômico liberal, cabia ao governo, numa tentativa de dar respostas a estes problemas, a adoção de atos de gestão orientados não pela certeza, mas pela experimentação. Temas como a ordenação das cidades, adoção de políticas econômicas - o enfrentamento, v.g., das carestias

\footnotetext{
${ }^{2}$ Como já afirmado alhures: "O paradigma da lepra, segundo FOUCAULT, é o da exclusão, ato pelo qual o contaminado era expulso de sua comunidade como forma de purificação. Já a peste tem como parâmetro não a exclusão, mas a inclusão, isto é, a concentração de toda a população de uma cidade que se põe sob quarentena, e sobre a qual se exerce um controle individual por intermédio de uma cadeia hierárquica de agentes estatais. " DE OLIVEIRA, Marcus Vinícius Xavier. Guerra ao terror: da biopolítica à bioguerra, Porto Velho: Edufro, 2013, p. 24.
} 
-, ou o enfrentamento dos crimes que viessem a ocorrer, a política governamental se regia pela experimentação, pela assunção de riscos quanto à (in) certeza de seu acerto.

Assim, quando o Estado, numa viragem bio-tanatopolítica, adota uma política sanitária no enfrentamento da epidemia de varíola mediante a inoculação de seu vírus em estado de latência no processo de vacinação, tanto o governo como a ciência médica não sabiam, de fato, a eficácia do tratamento (FOUCAULT, 2006, 73-79). Experimentou-se, pondo em risco a toda população que foi objeto desse ato de gestão sanitária.

Assim, exclusão e inclusão se conformam nas formas de experimentação através das quais o Estado, na gestação do espaço territorial e da população, busca dar soluções econômicas aos problemas inerentes ao próprio sistema econômico que o corrói, como um câncer, desde as entranhas.

E experimentação nesse caso não pode ser encarada como uma simples metáfora, mas também como uma possibilidade latente e concreta.

Em audiência pública realizada na Comissão de Direitos Humanos e Legislação Participativa, realizada em 31 de maio de 2006, no Senado Federal, foi apresentado o caso ocorrido na comunidade de São Raimundo de Pirativa, na cidade de Santana, Amapá, em que os moradores foram cooptados por pesquisadores brasileiros e americanos para servirem como cobaias humanas para o estudo da malária, com o financiamento de universidades brasileiras e americanas.

Os testes consistiam na exposição daqueles que "aderiram" ao programa ao contágio da doença, que se sabe, é endêmica na região, "trabalho" pelo qual receberiam R\$ 7,00 (sete reais) ao mês. Narrou-se o caso de um morador que pegou mais de dez malárias num único mês, e que desenvolveu cegueira e cirrose hepática por conta dos tratamentos a que teve de se submeter. ${ }^{3}$

Seria possível esta experimentação não fossem os residentes de São Raimundo de Pirativa um dos tantos rincões desse enorme território brasileiro excluídos do espaço de visibilidade?

Assim, se o território não se constitui no espaço geográfico delimitado por latitudes e longitudes, mas o locus de inscrição da vida humana no seio da política governamental de cariz

\footnotetext{
${ }^{3}$ Este fato estarrecedor, ocorrido na comunidade de São Raimundo de Pirativa, na cidade de Santana, Amapá, foi amplamente relatado na 4a Reunião Extraordinária da Comissão de Direitos Humanos e Legislação Participativa do Senado Federal, in http://www.senado.gov.br/web/cegraf/pdf/31052006/suplemento/00407.pdf, acessado em 10 de fevereiro de 2005, às 22:00:00.
} 
econômico-político, não qual não existe povo, mas população enquanto elemento essencialmente demográfico caracteriza a moderna sociedade política.

Esta inscrição, apesar de todo discurso em sentido oposto, não se guia pelos direitos e garantias fundamentais insertos nos textos constitucionais e internacionais, mas nas planilhas, leis orçamentárias, estatísticas policiais e sanitárias que a burocracia produz como forma de dar uma ordenação racional à irracionalidade e anarquia que se constitui o governo dos homens e das coisas (AGAMBEN, 2007, pp. 83 e ss.).

Território, portanto, não é o lugar delimitado juridicamente para a ação do Estado, mas o símbolo de um pertencimento: da vida humana ao poder soberano, que nos dias atuais se guia não pela ordem legal, mas pelo estado exceção, pela suspensão querida e consentida das leis na exceptio decidida por um governo submetido, em suas mínimas atuações, ao poder do mercado, razão pela qual, conforme Giorgio Agamben, não a normalidade, mas a crise é o signo da atuação governamental (AGAMBEN, 2012):

"Crise" e "economia" atualmente não são usadas como conceitos, mas como palavras de ordem, que servem para impor e para fazer com que se aceitem medidas e restrições que as pessoas não têm motivo algum para aceitar. "Crise" hoje em dia significa simplesmente "você deve obedecer! ". Creio que seja evidente para todos que a chamada "crise" já dura decênios e nada mais é senão o modo normal como funciona o capitalismo em nosso tempo. E se trata de um funcionamento que nada tem de racional.

Com efeito, vivemos, pois, numa época em que a palavra "crise" ganhou o status de palavra de ordem que está a legitimar aquilo que poderíamos denominar de excepcionalidade normalizada. Fala-se de crise para, mais do que explicar, justificar e tornar incontestáveis a adoção de determinadas práticas e/ou políticas que, não fosse a estrutura semântica e política do conceito, não cogitaríamos em nenhuma hipótese em nos submeter. Em outros termos, crise identificará, ao mesmo tempo, um julgamento orientado por aquele acrônimo geralmente atribuído a Pierre Bordieu - T.I.N.A ("There Is No Alternative") -, mas que na verdade foi inicialmente usado pela então Primeira Ministra inglesa Margareth Thatcher para justificar a implementação de políticas neoliberais e a derrocada de direitos sociais, mas também uma palavra de ordem idêntica àquela que se atribui a Frederico Guilherme II em resposta ao sapere aude kantiano: "pensem o quanto quiser desde que obedeçam".

Esta percepção é confirmada pela origem do vocábulo crise, que provém do grego kpíoıs (krisis), cuja utilização primeva pertencia à arte médica: no curso do tratamento, ao médico chegava um tempo de krisis, de julgamento, isto é, de tomar uma decisão acerca da sobrevivência ou não do paciente. Da arte médica, o conceito passou à teologia cristã para 
identificar o tempo da parousia, da segunda vinda, com a qual se consumará a história humana em seu momento crítico, isto é, de julgamento.

Nestes dois contextos, e nos que se seguiram em variados campos até chegarmos ao momento presente de economicização absoluta da vida e da política, crise identifica um momento de deficium, de resolução, de consumação, de julgamento e, portanto, de decisão sobre a excpetio, isto é, sobre aquilo que está, ao mesmo tempo, dentro e fora da norma. E por vivermos num período de crise contínua, o seu uso é o canal de normalização da excepcionalidade política.

Crise orçamentária, crise na segurança pública, crise econômica... crise. Onde a crise, enquanto conceito aberto e indeterminado que é se estabelece como parâmetro do governo, é a vida nua do homo sacer, e não o cidadão dos direitos que aparece em cena: uma vida insacrificável, porém matável (AGAMBEN, 2004).

\section{INCLUSÃO E EXCLUSÃO TERRITORIAL E O ABANDONO}

Assim, nada mais se parece a um grande laboratório de experimentação do que as grandes metrópoles de nosso tempo, na qual o viver bem ou o morrer não dependem mais de um gesto com o polegar do soberano, com o qual se determinava a morte do acusado. Não, hoje o gesto se transmudou na inação, na omissão, com a qual o soberano abandona parte da população à sua própria sorte, deixando aquela vida que deveria ser tutelada, guardada, protegida ao acaso; ou, quando age, fá-lo para dar uma resposta não à vida, mas ao mercado, este ser incorpóreo que a cada espirro põe (mantém!) a vida contemporânea sob o signo da crise.

Ban(d)ido (BATISTA, 2002, p. 36) ${ }^{4}$, e não cidadão, é o título a ser envergado pelo homem contemporâneo em sua busca, infrutífera e desarraigada pela vida boa. Numa sociedade em que o espetáculo, o consumo e a opulência são os únicos parâmetros de vida boa, não causa estranheza que qualquer ameaça ao status social, à comodidade, à segurança de uns poucos em detrimento de muitos se constitua no único fator relevante para determinar a ação ou inação do estado. E por isso, também, no regime de inclusão/exclusão territorial que

\footnotetext{
${ }^{4}$ Ou "estranho", como o afirmar Nilo Batista: "O estranho, ou seja, aquele que não é conhecido, que não integra as estruturas familiares e grupais da organização social germânica ou foi delas removido, é o grande alvo de suas práticas penais". BATISTA, Nilo. Matrizes ibéricas do sistema penal brasileiro $-1,2$ ed., Rio de Janeiro: REVAN, 2002, p. 36.
} 
dirige a ação policial nas cidades, amplamente legitimado pela mass media que se alimenta e se sustenta do medo que ela mesma incute.

Nas cidades de hoje, ninguém é mais estranho do que o seu próprio habitante, preso aos territórios que Ihe são impostos por serem ou não possuidores de bens e, consequentemente, de status social, territórios estes que, para os afortunados, não obstante a promessa de felicidade (shoppings, prédios de apartamentos com aparatos de segurança de última geração, condomínios fechados e hermeticamente encerrados para a vida que corre fora de seus muros), Ihes assegura somente o estranhamento ${ }^{5}$, o banimento em relação a seu semelhante.

Já no caso dos despossuídos, aquela luta diária pela sobrevivência, na qual segurança pública é sinônimo de UPP: pacifica-se não para que lhe seja prestado serviço público de qualidade a the permitir o pleno exercício da cidadania, mas para que as empresas de serviços e as concessionárias públicas possam "cobrar" pelos serviços dantes desviados pela "pirataria" e pelos "gatos", e para que o mercado imobiliário possa se apropriar, por todos os meios possíveis, desses rincões que, com a pacificação, se tornam atrativos ao investimento privado, nacional e ou internacional.

Assim, as cidades se constituem em grandes máquinas antropológicas de inclusão e exclusão, no qual o princípio da territorialidade permite aquela distinção importante e necessária para o regime econômico: consumidores e não consumidores; ricos e pobres; espaços de (pseudo)segurança e espaços de sobrevivência, apesar ou mesmo contra o Estado.

\section{À GUISA DE CONCLUSÃO...}

Que a territorialidade, apesar de seu propagado deficium, ainda seja eficaz na conformação includente-excludente da sociedade contemporânea se deve, primeiramente, a seu caráter perene enquanto princípio político fundamental do pensamento ocidental, mas também pelo papel que ele joga no aspecto de planejamento governamental.

A divisão do território de uma cidade em diversos setores - produtivos, de moradia, de comércio, governamental etc - implica numa decisão política sobre o como, o quem e o de que

\footnotetext{
5 Para ficarmos em Agamben, mais uma vez, estes "territórios de felicidade" mais se aparentam ao purgatório, que na teologia tomista tem um caráter punitivo mediante a privação, enquanto o inferno um caráter punitivo aflitivo. Privação de quê? Da perpétua visão de deus. (AGAMBEN, Giorgio. La comunità che viene, Torino: Bollati Boringhieri, 2001, p. 11.) Mas como, em essa sociedade pós-metafísica (?), Deus não morreu, tornou-se dinheiro (um meio sem fim), os territórios de felicidade nada mais são do que espaços de pura privação. (AGAMBEN, Deus não morreu....).
} 
forma um determinado espaço pode e deve ser ocupado, o que, per se, não é ruim. O problema é quando esta conformação territorial é decidida apesar ou contra a própria sociedade. Que espaços não ordenados sejam encarados como locus naturais de ocupação da miséria, nas quais seus moradores são abandonados até que a necessidade de 'pacificação' se faça presente para atender às demandas do mercado. Mas também, que espaços públicos - e serviços públicos sejam privatizados, sem que este fato, em si mesmo maléfico, seja encarado como uma decorrência natural.

De naturalizações em naturalizações, inclusão e exclusão territorial continuarão a ser o que são: dispositivos políticos segundo os quais a vida é incluída ou excluída da esfera de proteção do direito; e, onde o direito e as garantias fundamentais não operam eficácia, soberana é a polícia que exerce o seu poder-violência (BENJAMIN, 2012, p. 59) de acordo com as decisões (im)políticas próprias ao estado de exceção (AGAMBEN, 2000, pp. 103-108, DE OLIVEIRA, 2013, pp. 61-62).

Giorgio Agamben, analisando este aspecto sob o signo da metrópole, orientado pelos léxicos foucaultianos dispositivo, subjetivação e sujeitamento, faz algumas afirmações importantes para a compreensão do tema (AGAMBEN, 2007):

Afirmei que a cidade é um dispositivo, ou um grupo de dispositivos. A teoria referida anteriormente era a ideia sumária de que se pode dividir a realidade em, de um lado, os humanos e os seres viventes, e de outro, os dispositivos que continuamente os capturam e os retêm. No entanto, o terceiro elemento fundamental que define um dispositivo, creio que também para Foucault, são os processos de subjetivação que resultam do corpo a corpo entre o indivíduo e os dispositivos. Não há dispositivo sem um processo de subjetivação; falar de dispositivo é necessário que exista um processo de subjetivação. Sujeito quer significar duas coisas: o que leva um indivíduo a assumir e atar-se a uma individualidade e uma singularidade, mas também significa a submissão a um poder externo. Não há processo de subjetivação sem estes dois aspectos: assunção de uma identidade e sujeição a um poder externo.

O que muitas vezes falta, inclusive para os movimentos, é a consciência desta relação, a consciência de que cada vez que alguém assume uma identidade alguém também é subjugado. Obviamente, isto também é complicado pelo fato de que os dispositivos modernos não somente auxiliam na criação de uma subjetividade, mas também, e na mesma medida, nos processos de dessubjetivação. Isto pode ter sido sempre assim, pensem na confissão, que deu forma à subjetividade moderna (a confissão formal dos pecados), ou a confissão jurídica, que todos experimentamos hoje. A confissão sempre supôs tanto a criação de um sujeito como a negação de um sujeito, por exemplo, na figura do pecador e do confessor, sendo claro que a assunção de uma subjetividade vai junto com um processo de subjetivação. O ponto, então, é que atualmente os dispositivos são cada vez mais dessubjetivantes, de forma 
que é difícil identificar os processos de subjetivação que eles criam. Mas a metrópole é também um espaço no qual um tremendo processo de criação de subjetividade tem lugar. Sobre isto não sabemos muito. Quando digo que necessitamos conhecer estes processos, não somente me refiro à análise, muito importante por certo, sobre a natureza sociológica ou econômica ou social destes processos de subjetivação; refiro-me ao nível ontológico, à questão spinoziana da capacidade para agir dos sujeitos; isto é, o que, no processo através do qual o sujeito de alguma forma resta atado a uma subjetividade, leva a uma mudança, a um aumento ou diminuição de sua capacidade de agir. Carecemos desse conhecimento e, provavelmente, isso faz com que os conflitos metropolitanos dos quais somos testemunhas sejam bastante opacos.

Creio que uma confrontação com os dispositivos metropolitanos somente será possível quando penetrarmos de uma forma mais articulada, mais profunda nos processos de subjetivação que a metrópole implica. Porque creio que o resultado dos conflitos dependerá da capacidade de agir e intervir nos processos de subjetivação, com o fim de alcançar esse momento que eu denominaria de ingovernabilidade, do ingovernável que pode fazer naufragar ao poder em sua forma de governo, o ingovernável que, creio, é sempre o começo e a linha de fuga de toda política.

De semelhante forma, Nilo Batista, ao apresentar o livro de Davi Tangerino, afirma a necessidade de o pensamento crítico ao Direito (sistema) Penal - no caso encarnado pelo autor - assumir a subjetividade do rei verotestamentário e mirar bem na testa do monstro, pois "[...] o gigante um dia cairá" (TANGERINO, 2011).

Haveria uma tarefa mais urgente para o pensamento crítico contemporâneo do que, derrubando o gigante, tornar ingovernável a máquina antropológica de inclusão e exclusão, na qual o sistema penal é o principal dispositivo e, assim, dar lugar à política que vem?

\section{REFERÊNCIAS}

AGAMBEN, Giorgio. Means without end: notes on politics, trd. Vicenzo Binetti and Cesare Casarino, Minneapolis: University of Minnesota Press, 2000.

La comunitàche viene, Torino: Bollati Boringhieri, 2001.

Homo sacer: o poder soberano e a vida nua I, trd. Henrique Burigo, Belo Horizonte: Ed. UFMG, 2004.

Il regno e la gloria: per una genealogia teologica dell'economia e del governo. Homo sacer, II.2, Vicenza: Neri Pozza, 2007.

Metropolis, disponível em http://www.egs.edu/faculty/giorgioagamben/articles/metropolis/, acessada em 20/06/2007, às 12:00:00.

"Deus não morreu. Ele tornou-se dinheiro", trd. Selvino Assmann, Instituto Humanistas Unisinos, 30 de agosto de 2012. Disponível em http://www.ihu.unisinos.br/noticias/512966giorgio-agamben, acessado em 30/08/2012, às 23:30:00.

Política do exílio, trad. Marcus Vinícius Xavier de Oliveira, in DANNER, Fernando, DANNER, Leno Francisco. Temas de filosofia política contemporânea, Porto Alegra: FI, 2013, pp. 33-50. 
BATISTA, Nilo. Matrizes ibéricas do sistema penal brasileiro - I, 2 eds., Rio de Janeiro: REVAN, 2002.

BENJAMIN, Walter, BARRENTO, João (Org.). "Sobre a crítica do poder como violência", in O anjo da história, trd. João Barrento, Belo Horizonte: Autêntica, 2012.

JOSÉ BREMER, Juan. De Westfalia a post-Westfalia: hacia un nuevo orden internacional, Cuidad de México: Universidad Nacional Autonoma de México/Instituto de Investigaciones Jurídicas, 2013.

CASTRO, Thales. Teoria das Relações Internacionais, Brasília: FUNAG, 2012.

COSTA, Ricardo, ZIERER, Adriana. Boécio e Ramon Llul: a roda da fortuna, princípio e fim dos homens. Disponível em http://www.hottopos.com/convenit5/08.htm, acessado em 20/05/2011, às 14:00:00.

DE OLIVEIRA, Marcus Vinícius Xavier. Guerra ao terror: da biopolítica à bioguerra, Porto Alegre: $\mathrm{Fi}, 2014$.

FOUCAULT, Michel. Em defesa da sociedade, trd. Maria E. Galvão, São Paulo: Martins Fontes, 2002.

"Omnes et singulatim": uma crítica da Razão Política, In DA MOTTA, Manoel Barros (Org.). Ditos e escritos IV - estratégia, poder - saber, trad. Vera Lúcia A. Ribeiro, Rio de Janeiro: Forense Universitária, 2003.

História da sexualidade I: a vontade de saber, 16 ed., trad. Maria T. da C. Albuquerque e J. A. Guilhon Albuquerque, 2005.

Seguridad, territorio, población, trd. Horacio Pons, Buenos Aires: Fondo de Cultura Económica, 2006.

A governamentalidade, In Microfísica do poder, 23 ed., trad. Roberto Machado e Angela Loureiro de Souza, Rio de Janeiro: Graal, 2007.

HABERMAS, Jürgen. Intolerance and discrimination, International Journal of Constitucional Law, vol. 1, n. 1, 2003, pp. 2-12.

HOBBES, Thomas. Leviatã, trd. João Paulo Monteiro e Maria B. N. da Silva, São Paulo: Nova Cultura, 1997.

MIRANDA, Jorge. Teoria do Estado e da Constituição, Rio de Janeiro: Forense, 2005.

SANTOS, Boaventura de Sousa. Os processos da globalização. Disponível em http://www.eurozine.com/articles/2002-08-22-santos-pt.html, acessado em 20/02/2011, às 23:35:00.

BRASIL. SENADO FEDERAL. COMISSÃO DE DIREITOS HUMANOS E LEGISLAÇÃO PARTICIPATIVA. Ata da 4a Reunião Extraordinária da Comissão de Direitos Humanos e Legislação Participativa do Senado

Federal,

In: http://www.senado.gov.br/web/cegraf/pdf/31052006/suplemento/00407.pdf, acessado em 10 de fevereiro de 2005, às 22:00:00. 
TANGERINO, Davi de Paiva Costa. Culpabilidade, Rio de Janeiro: Campus Jurídico, 2011.

Trabalho enviado em 09 de janeiro de 2017.

Aceito em 06 de abril de 2017. 